\title{
PDGF- $\beta$ Receptor Expression in the Dorsocaudal Brainstem Parallels Hypoxic Ventilatory Depression in the Developing Rat
}

\author{
VUKMIR VLASIC, NARONG SIMAKAJORNBOON, EVELYNE GOZAL, AND DAVID GOZAL \\ Kosair Children's Hospital Research Institute, Departments of Pediatrics, Pharmacology and Toxicology \\ [V.V., E.G., D.G.], University of Louisville School of Medicine, Louisville, KY 40202, U.S.A.; and \\ Constance S. Kaufman Pediatric Pulmonary Research Laboratory, Departments of Pediatrics [V.V., N.S.], \\ Tulane University School of Medicine, New Orleans, LA 70112, U.S.A.
}

\section{ABSTRACT}

The temporal trajectory of platelet-derived growth factor (PDGF)- $\beta$ receptor activation within the dorsocaudal brainstem parallels that of the mild hypoxic ventilatory depression (HVD) seen in adult rats. We hypothesized that enhanced PDGF- $\beta$ receptor activity may account for the particularly prominent HVD of developing mammals. To study this issue, 2-, 5-, 10-, and 20-d-old rats underwent hypoxic challenges $\left(10 \% \mathrm{O}_{2}\right.$ for 30 min) after pretreatment with either vehicle (Veh) or the selective PDGF- $\beta$ receptor antagonist CGP57148B (intraperitoneal 100 $\mathrm{mg} / \mathrm{kg}$ ). The developmental characteristics and magnitude of the the PDGF- $\beta$ receptor blocker. However, HVD was markedly attenuated by CGP57148B, and such effect, although still present, gradually abated with increasing postnatal age $[p<$ 0.001 , analysis of variance (ANOVA)]. Hypercapnic ventilatory responses were not affected by CGP57148B. The expression of PDGF- $\beta$ receptor in the dorsocaudal brainstem was assessed by immunoblotting and confirmed progressively decreasing expression with maturation. We conclude that PDGF- $\beta$ receptor activation during hypoxia is an important contributor to HVD at all postnatal ages but more particularly in the immature rat. (Pediatr Res 50: 236-241, 2001) peak hypoxic ventilatory response (HVR) were not modified by

\author{
Abbreviations \\ ANOVA, analysis of variance \\ BW, body weight \\ GABA, $\gamma$-aminobutyric acid \\ HVD, hypoxic ventilatory depression \\ HVR, hypoxic ventilatory response \\ NMDA, $N$-methyl-D-aspartate \\ NTS, nucleus tractus solitarius \\ PBS, phosphate-buffered saline \\ PDGF, platelet-derived growth factor \\ PMSF, phenylmethyl sulfonyl fluoride \\ SDS, sodium dodecyl sulphate \\ $\dot{\mathbf{V}}_{\mathbf{E}}$, minute ventilation \\ Veh, vehicle \\ $\mathbf{V}_{\mathrm{T}}$, tidal volume \\ f, respiratory frequency \\ nNOS, neuronal nitric oxide synthase \\ PKC, protein kinase $\mathrm{C}$ \\ TBS-T, TBS-Tween 20 \\ DTT, dithiothreitol \\ Tris, tris(hydroxymethyl)aminomethane \\ CNS, central nervous system
}

The acute ventilatory response to hypoxia in adult mammalian species is biphasic. In the rat, after the initial ventilatory increase (which is primarily mediated by integration of peripheral chemoreceptor afferent input) there is a subsequent mild decrease in ventilation to levels that are lower than the peakearly ventilatory increase, although they exceed those during normoxia(1). In most neonatal mammals, however, this second phase of the HVR, also named HVD, is particularly prominent,

Received July 18, 2000; accepted January 23, 2001.

Correspondence to: David Gozal, M.D., Kosair Children's Hospital Research Institute, University of Louisville, 570 S. Preston Street, Ste. 321, Louisville, KY 40202, U.S.A.; e-mail: d0goza01@gwise.louisville.edu

Supported by grants from the National Institutes of Health (HL-65270 HL-63912, HL-66358, P20 RR-15576) and the American Heart Association (AHA- 0050442N). and ventilation is usually reduced below normoxic levels (2). The mechanisms underlying HVD are complex and probably involve interaction of multiple neural pathways. In addition to decreases in oxygen consumption (3), GABA and adenosine release during hypoxia will further add to HVD, as will the relative paucity of nNOS expression within several brainstem nuclei mediating HVR (4-7). Furthermore, several other mechanisms involving opioid receptors and local release of various neuroactive peptides have also been implicated in HVD (reviewed in ref. 8).

In a recent study, we found that activation of PDGF- $\beta$ receptors within the NTS modulated HVD in the adult freely behaving rat, as well as in the adult mouse. Indeed, pharmacological inhibition or diminished expression of PDGF- $\beta$ re- 
ceptors within the dorsocaudal brainstem almost completely abolished the typical ventilatory decline that characteristically occurs with ongoing hypoxia (9). In addition, we found that both PDGF-B chain and PDGF- $\beta$ receptors, but not PDGF- $\alpha$ receptors, were abundantly expressed in a large proportion of NTS neurons undergoing functional recruitment during hypoxia and that acute hypoxia-induced PDGF-B chain mRNA transcription (9). Although the mechanisms by which the PDGF-BB PDGF- $\beta$ receptor system affects respiratory control are as yet unclear, we hypothesized that the developmental characteristics of HVD could be mediated at least in part by postnatal changes in PDGF- $\beta$ receptor expression and/or function. In other words, the more pronounced HVD in the neonatal rat would be associated with higher expression of PDGF- $\beta$ receptor within the dorsocaudal brainstem.

\section{METHODS}

Animals. The experimental protocols were approved by the Institutional Animal Use and Care Committee and are in close agreement with the National Institutes of Health guide for the care and use of laboratory animals. All efforts were made to minimize animal suffering, reduce the number of animals used, and use alternatives to in vivo techniques. Time-pregnant Sprague-Dawley rats were obtained from a commercial breeder (Charles River Laboratories, Wilmington, MA, U.S.A.), and delivery times were recorded.

Ventilatory responses to hypoxia and hypercapnia. For hypoxic ventilatory studies, rat pups were randomly selected from every litter at postnatal d 2, 5, 10, and $20(\mathrm{n}=10$ per age group). These ages have been previously shown as representative of maturational changes in the biphasic ventilatory response to hypoxia $(2,7)$. Additional rat pups $(\mathrm{n}=$ four per age group) underwent hypercapnic ventilatory challenges. For these experiments, as well as for the expression experiments delineated below, a total of 236 pups were used from 22 litters. Litters were routinely reduced to 12 pups by randomly euthanizing excess animals at birth with a pentobarbital overdose. For all experiments, similar numbers of male and female pups were used (120 males and 116 females).

Ventilatory recordings. Respiratory measures were continuously acquired in the freely behaving, unrestrained animal placed in a previously calibrated 0.5 L-Plexiglas ${ }^{\mathrm{TM}}$ chamber using whole-body plethysmography (Buxco Electronics, Troy, NY, U.S.A.) (10-13). To minimize the long-term effect of signal drift due to temperature and pressure changes outside the chamber, a reference chamber of equal size in which temperature was measured using a T-type thermocouple was used. In addition, a correction factor was incorporated into the software routine to account for inspiratory and expiratory barometric asymmetries (13). Environmental temperature was maintained within $29-32^{\circ} \mathrm{C}$, which corresponds to usual environmental temperatures recorded in the nest. A calibration volume of 0.1 $\mathrm{mL}$ of air was repeatedly introduced into the chamber before and upon completion of recordings. At least $30 \mathrm{~min}$ before the start of each protocol, animals were allowed to acclimate to the chamber, in which humidified air $(90 \%$ relative humidity) warmed at $30^{\circ} \mathrm{C}$ was passed through at a rate of $1 \mathrm{~L} \cdot \mathrm{min}^{-1}$ using a precision flow pump-reservoir system. Pressure changes in the chamber due to the inspiratory and expiratory temperature changes were measured using a high-gain differential pressure transducer (Validyne, Model MP45-1, Northridge, CA, U.S.A.). Analog signals were continuously digitized and analyzed on-line by a microcomputer software program (Buxco Electronics). A rejection algorithm was included in the breath-by-breath analysis routine and allowed for accurate rejection of motion-induced artifacts. $V$ t, $f$, and $\dot{V}_{\mathrm{E}}$ were computed and stored for subsequent off-line analysis.

Protocol. Ventilatory challenges with $10 \% \mathrm{O}_{2}$ in $\mathrm{N}_{2}$ lasting for $30 \mathrm{~min}$ were initially performed in each rat pup after intraperitoneal administration of Veh $(0.2 \mathrm{~mL}$ of normal saline). Gas switches were performed by rapidly bleeding the premixed gas mixture into the recording chamber. Animals were allowed to recover with their mother in room air for $24 \mathrm{~h}$ and were then injected with the selective PDGF- $\beta$ receptor antagonist, CGP 57148B (100 mg/kg intraperitoneal in $0.2 \mathrm{~mL})$ (14). Thirty min after CGP 57148B administration, hypoxic challenges were repeated. In a subset of three animals per age group, challenges were repeated after a second dose of normal saline to ascertain reproducibility and variability of the response at various postnatal ages. The adequacy of the CGP 57148B dosages and experimental time frames has been previously validated (9). In brief, the dose of CGP 57148B was selected from a dose-response curve in the adult rat, as well as by doubling the dose of CGP 57148B, leading to maximal reduction of tyrosine phosphorylation of the receptor during hypoxic conditions (9). For hypercapnic ventilatory challenges, $5 \% \mathrm{CO}_{2}$ balance room air was administered for 30 min after the same experimental template as that described for hypoxic runs. This time frame provides adequate expression of HVD and does not modify the ventilatory response to a subsequent challenge $(7,15,16)$.

Immunoblotting of PDGF- $\beta$ receptor. Pooled dorsocaudal brainstem tissues ( $\mathrm{n}=$ five or six animals per sample), primarily corresponding to the NTS, were harvested at each postnatal age and from adult rats by punch sampling using a 17-gauge thin-walled hypodermic needle, as previously described (17). Six separate experiments corresponding to a total of $42-48$ animals per postnatal age were conducted. Samples were homogenized in lysis buffer (PBS pH 7.6, 0.5\% sodium deoxycholate, $1 \%$ Nonidet P40, $0.1 \%$ SDS, $20 \mathrm{mM}$ sodium orthovanadate, $10 \mu \mathrm{g} / \mathrm{mL}$ aprotinin, $10 \mu \mathrm{g} / \mathrm{mL}$ leupeptin, and 0.5 mM PMSF). Crude synaptosomes were obtained by centrifugation of the homogenates for $10 \mathrm{~min}$ at $1000 \mathrm{~g}$ and further centrifugation of supernatants at $15,000 \mathrm{~g}$ for $30 \mathrm{~min}$. The resultant pellets were resuspended and assayed for protein content (Bio-Rad, Hercules, CA, U.S.A.). Five-hundred $\mu \mathrm{g}$ of protein were used for the immunoprecipitation of PDGF- $\beta$ receptor protein and incubated overnight at $4^{\circ} \mathrm{C}$ with $12 \mu \mathrm{g}$ of PDGF- $\beta$ receptor antibody (UBI, Lake Placid, NY, U.S.A.) in a total volume of $500 \mu \mathrm{L}$, after which $30 \mu \mathrm{L}$ of protein A Sepharose were added and incubated for $1 \mathrm{~h}$ at $4^{\circ} \mathrm{C}$. The immunoprecipitates were washed three times with lysis buffer and resuspended in a mixture of $20 \mu \mathrm{L}$ lysis buffer and $20 \mu \mathrm{L}$ SDS-sample buffer $(0.5 \mathrm{M}$ Tris, $\mathrm{pH} 6.5,20 \%$ glycerol, $4 \%$ SDS, $100 \mathrm{mM}$ DTT). Proteins were separated by electrophore- 
sis on a $4 \%$ to $12 \%$ Tris-glycine gradient gel (Novex, San Diego, CA, U.S.A.), and transferred to a $0.2-\mu \mathrm{m}$ nitrocellulose membrane. Nonspecific binding was blocked by $1-\mathrm{h}$ incubation with $5 \%$ BSA in TBS-T. The membrane was incubated overnight at $4^{\circ} \mathrm{C}$ with PDGF- $\beta$ receptor antibody (1:300; UBI). Membranes were washed with TBS-T and incubated with secondary antibodies for $1 \mathrm{~h}$. After extensive washing, proteins were detected by enhanced chemiluminescence (Amersham, Arlington Heights, IL, U.S.A.).

Data analysis. Values are reported as mean \pm SEM unless indicated otherwise. Baseline ventilation before each hypoxic run was defined as the average of ventilatory measures during the 3-min period immediately preceding the gas switch. For ventilatory challenges, mean $\dot{V}_{\mathrm{E}}$ values over a 1-min period were calculated and the peak average $\dot{\mathrm{V}}_{\mathrm{E}}$ value over $1 \mathrm{~min}$ throughout the hypoxic run was considered as representative of the HVR. To normalize across the various postnatal ages, the overall peak $\dot{\mathrm{V}}_{\mathrm{E}}$ increase during hypoxia was calculated using the normoxic baseline preceding each challenge and was therefore expressed as percent baseline. Similarly, the lowest average $\dot{\mathrm{V}}_{\mathrm{E}}$ measured over a 1-min period was defined as corresponding to HVD. Again, to normalize across ages, HVD was calculated as percent baseline.

For western blot procedures, semiquantitative analysis of the bands was performed by scanning densitometry. Comparisons across treatment groups of numerical data were performed using either $t$ tests or two-way ANOVA (treatment and time, or hypoxia/hypercapnia) followed by Newman-Keuls post hoc tests, as appropriate. A $p$ value of $<0.05$ was considered to achieve statistical significance.

\section{RESULTS}

Ventilatory measurements. Mean weights and baseline ventilatory measures for the four postnatal ages are shown in Table 1.

In all pretreated animals, an initial $\dot{\mathrm{V}}_{\mathrm{E}}$ increase occurred with the hypoxic stimulus onset and was considered to primarily represent peripheral chemoreceptor contributions (Figs. 1 and $2)$. As previously shown $(2,7,15,16)$, an age-dependent increase in the magnitude of the HVR was apparent. However, the magnitude of HVR was unchanged by pretreatment with CGP 57148B (Figs. 1 and 2), and no changes in either $f$ or VT occurred when Veh and CGP 57148B were compared ( $p=$ NS). Similarly, CGP 57148B did not affect respiratory drive $(\mathrm{VT} / \mathrm{Ti})$ or timing (Ti/TTOT). Taken together, these data suggest that PDGF- $\beta$ receptor inhibition does not modify peripheral chemoreceptor-mediated responses at any postnatal age.

A significant ventilatory decline from the early-peak $\dot{V}_{\mathrm{E}}$ response occurred in all developing animals over time, such that by 30 min into the hypoxic challenge $\dot{V}_{\mathrm{E}}$ had decreased below room air values in 2-, 5-, and 10-d-old rat pups (Figs. 1
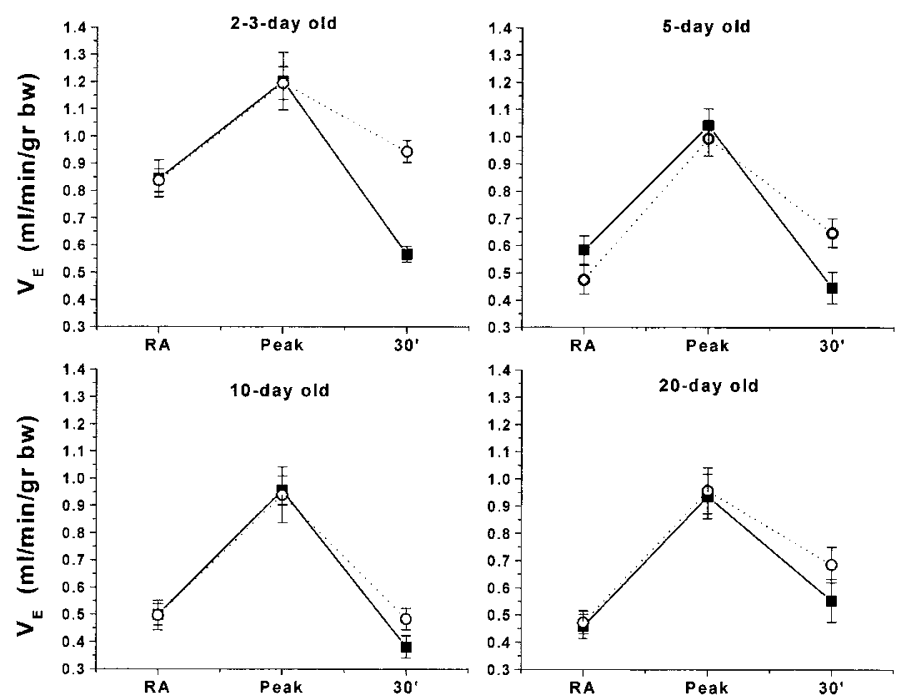

Figure 1. Mean HVR in 2-, 5-, 10-, and 20-d-old rat pups after receiving the PDGF- $\beta$ receptor antagonist CGP 57148B (open circles) or Veh (closed squares). To normalize across the groups, ventilation is expressed as $\mathrm{ml} \cdot \mathrm{min}^{-1} \cdot \mathrm{g}^{-1} \mathrm{BW}$.

and 3). In 20-d-old rat pups, late hypoxic ventilatory measurements remained $17.8 \pm 7.2 \%$ above room-air baseline $(p<$ 0.01 versus any other rat pup group). Thus, with increasing postnatal age, the magnitude of the biphasic ventilatory response to hypoxia was diminished $(p<0.02$, two-way ANOVA).

In CGP 57148B-treated conditions, HVD was markedly attenuated in the youngest animals (Figs. 1 and 3), and although this attenuation was present at all postnatal ages, the magnitude of CGP 57148B effect on HVD diminished with increasing postnatal age (Figs. 1 and $3 ; p<0.0001$ ANOVA).

Although significant increases in overall ventilatory responses to hypercapnia occurred with advancing maturation, the magnitude of the ventilatory response to hypercapnia at any given postnatal age was similar in Veh- and CGP 57148Btreated animals (Fig. $4 ; p=\mathrm{NS}$ ).

Immunoblots of PDGF- $\beta$ receptor in the dorsocaudal brainstem. Western blotting of protein equivalents from tissue homogenates derived from pooled dorsocaudal brainstem tissue at various postnatal ages revealed decreasing PDGF- $\beta$ receptor expression with maturation (Fig. $5 ; \mathrm{n}=6 ; p<0.003$ ANOVA).

\section{DISCUSSION}

This study shows that with increased maturation there is decreasing expression of PDGF- $\beta$ receptor within the dorsocaudal brainstem, and that these postnatal changes in receptor expression are intimately associated with their modulatory

Table 1. Mean ( \pm SEM) baseline ventilatory and weight measurements in 2-, 5-, 10-, and 20-d-old rat pups

\begin{tabular}{lcccc}
\hline & $2-\mathrm{d}(\mathrm{n}=10)$ & $5-\mathrm{d}(\mathrm{n}=10)$ & $10-\mathrm{d}(\mathrm{n}=10)$ & $20-\mathrm{d}(\mathrm{n}=10)$ \\
\hline $\mathrm{V}_{\mathrm{T}}(\mu \mathrm{L} / \mathrm{g} \mathrm{BW})$ & $4.5 \pm 0.3$ & $3.7 \pm 0.3$ & $3.0 \pm 0.2$ & $3.3 \pm 0.2$ \\
$\mathrm{f}(\mathrm{breaths} / \mathrm{min})$ & $182.3 \pm 4.5$ & $158.4 \pm 5.4$ & $164.0 \pm 4.9$ & $154.4 \pm 4.6$ \\
$\dot{\mathrm{V}}_{\mathrm{E}}(\mathrm{mL} / \mathrm{min} / \mathrm{g} \mathrm{BW})$ & $0.82 \pm 0.04$ & $0.59 \pm 0.03$ & $0.50 \pm 0.03$ & $0.46 \pm 0.03$ \\
Weight $(\mathrm{g})$ & $4.3 \pm 0.5$ & $10.3 \pm 1.7$ & $17.4 \pm 2.1$ & $48.8 \pm 2.4$ \\
\hline
\end{tabular}




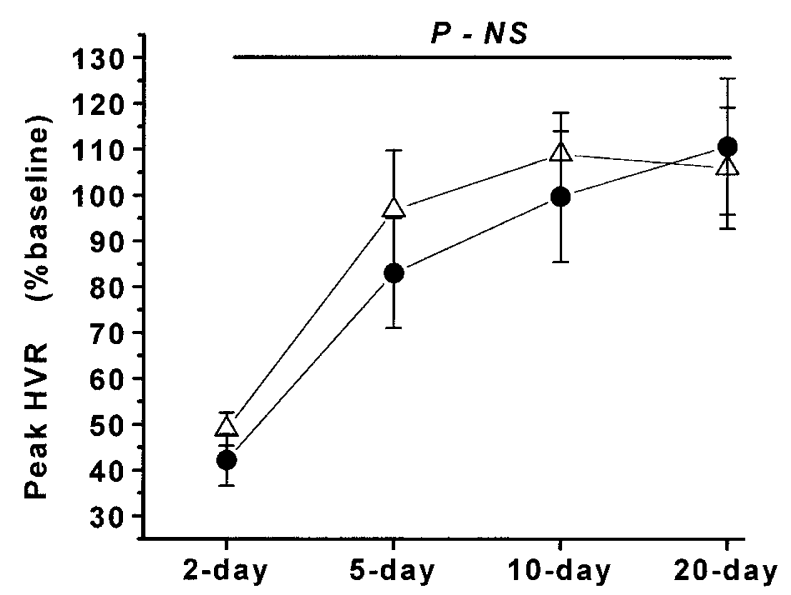

Figure 2. Mean peak HVR expressed as change from corresponding baseline in 2-, 5-, 10-, and 20-d-old rat pups after receiving the PDGF- $\beta$ receptor antagonist CGP 57148B (open triangles) or Veh (closed circles). No significant differences in HVR occurred at any postnatal age.

effect on the late phase of the hypoxic response in the developing rat without affecting HVR.

Ventilatory responses. Our ventilatory measurements during both early and late respiratory responses to hypoxia in control conditions are in close agreement with similar experiments by Eden and Hanson (2), and our previous findings (7). Indeed, significant enhancements of the peak $\dot{\mathrm{V}}_{\mathrm{E}}$ response and reduced HVD occurred with increasing postnatal age $(2,7)$. Because hypoxia induces significant reductions in oxygen consumption $\left(\dot{\mathrm{V}}_{\mathrm{O} 2}\right)(18)$, we attempted to partially circumvent this problem by maintaining environmental temperature near the thermoneutral range during ventilatory measurements. However, it is unlikely that the PDGF- $\beta$ receptor inhibitor modified metabolic rates or thereby significantly affected our results. Indeed, CGP 57148B did not alter the magnitude of the peak $\dot{\mathrm{V}}_{\mathrm{E}}$ response, and the latter should have been increased if CGP 57148B had increased metabolic rates. In addition, because thermal conditions were similar before and after CGP 57148B administration, it is unlikely that differences in ventilatory measurements resulted from hypoxia-induced $\dot{\mathrm{V}}_{\mathrm{O} 2}$ changes. Nonetheless, one cannot exclude with certainty the possibility that intraperitoneal administration of a selective PDGF- $\beta$ receptor blocker such as CGP 57148B may have affected metabolic rates, because the time course and metabolic consequences of such inhibitors in developing animals during normoxia and hypoxia are currently unknown.

A substantial body of evidence supports a major role for brainstem glutamatergic mechanisms in the $\dot{\mathrm{V}}_{\mathrm{E}}$ enhancements that accompany application of a hypoxic stimulus (19). However, whereas glutamate receptors are critical to HVR in the adult rat $(20,21)$, their contribution emerges as much more modest in the neonatal rat $(15,16)$. Although reduced expression of glutamate receptors within some of the caudal brainstem regions involved in HVR may certainly play a role in the developmental characteristics of HVR, it is clear that after the peak excitatory ventilatory effects of hypoxia have occurred, HVD will emerge rather rapidly in the immature rat. From our current experiments, it does not appear that a tonic inhibitory

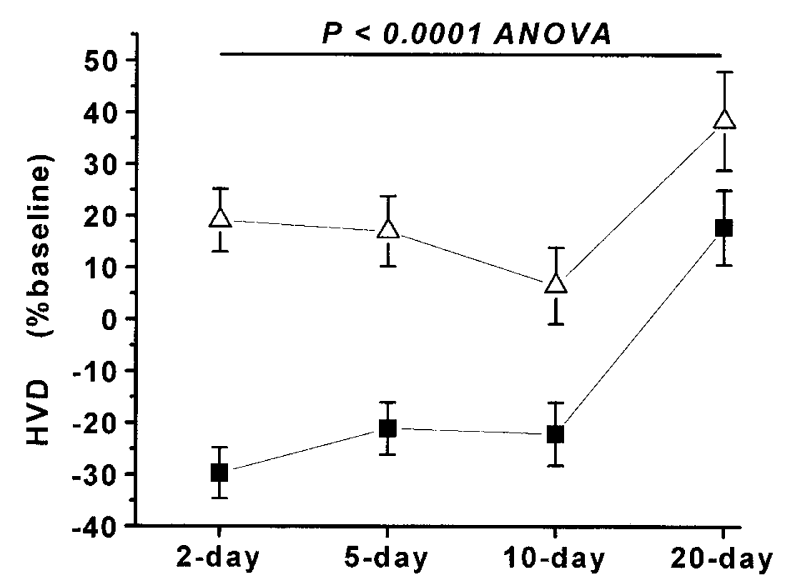

Figure 3. Mean values for HVD expressed as change from corresponding baseline in 2-, 5-, 10-, and 20-d-old rat pups after receiving the PDGF- $\beta$ receptor antagonist CGP 57148B (open triangles) or Veh (closed circles). HVD was attenuated at all ages (Veh vs CGP 57148B: $p<0.01$ at any postnatal age), and the magnitude of HVD reduction exhibited age dependency $(p<$ 0.0001 , ANOVA).
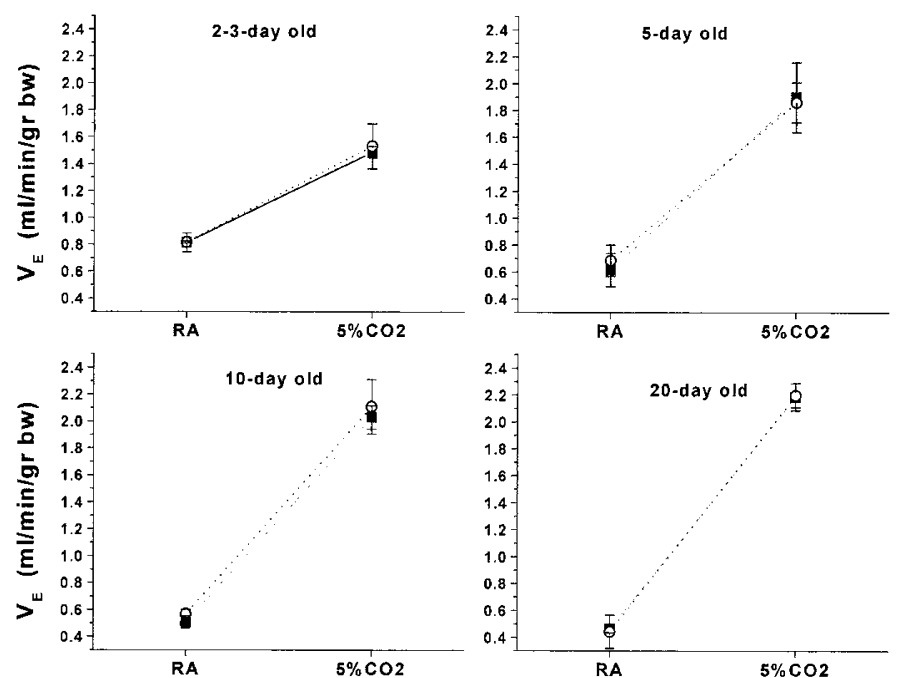

Figure 4. Mean hypercapnic ventilatory responses in 2-, 5-, 10-, and 20-d-old rat pups after receiving the PDGF- $\beta$ receptor antagonist CGP 57148B (open circles) or Veh (closed squares). To normalize across the groups, ventilation is expressed as $\mathrm{ml} \cdot \mathrm{min}^{-1} \cdot \mathrm{g}^{-1} \mathrm{BW}$. Although hypercapnic ventilatory responses were enhanced with advancing postnatal age, no differences occurred after CGP 57148B treatment ( $p=$ NS).

effect of PDGF- $\beta$ receptor activity was present on these excitatory pathways, as pretreatment with CGP 57148B failed to modify the characteristics of HVR at any postnatal age. Thus, the effect of PDGF- $\beta$ receptor activity appears to directly involve the generation of HVD rather than indirectly affect the magnitude and temporal characteristics of HVR.

The mechanism underlying such direct effect on HVD is unknown. However, one potential mechanism could involve functional interactions between glutamate and PDGF- $\beta$ receptors as proposed by Valenzuela and colleagues while studying the effect of the PDGF BB isoform on glutamate receptor function in hippocampal neurons (22). These investigators proposed that activation of PDGF- $\beta$ receptors would lead to downstream activation of a signaling cascade involving forma- 


\section{PDGF $\beta$ Receptor}
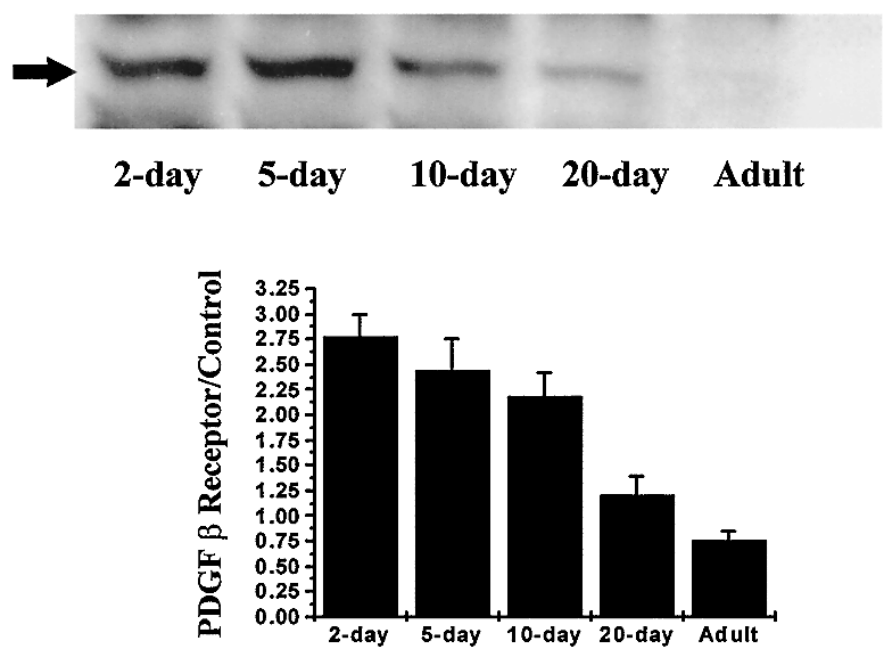

Figure 5. In the upper panel, a representative western blot of PDGF- $\beta$ receptor in protein equivalents of tissue homogenates harvested from dorsocaudal brainstem of 2-, 5-, 10-, and 20-d-old rat pups and adult rats. In the lower panel, mean $( \pm \mathrm{SEM})$ scanning densitometer readings of six separate western blots for PDGF- $\beta$ receptor expressed for each age group as the percentage value from the corresponding control lysate band. A significant age-dependent decrease in PDGF- $\beta$ receptor occurs with maturation $(p<$ 0.003 , ANOVA)

tion of phosphoinositol triphosphate. This in turn would lead to the undocking of glutamate receptor-activated PKC, which would down-regulate the inotropic current elicited by activation of the glutamate receptor (22). Although the intracellular signaling pathways involved in glutamate receptor channelmediated ionic influxes during acute hypoxia are not yet fully characterized, we have previously ascribed important putative roles for nNOS, PKC, and tyrosine kinases (7, 17, 23-30). Furthermore, we have shown that the activation of these signaling pathways is transient. Indeed, at time points corresponding to HVD the activities of both PKC and other kinases, such as c-Jun- $N$-terminal kinase, will have returned to near normoxic baseline values in the brainstem of adult rats $(29,31)$. The transient nature of these events is compatible with the putative mechanisms proposed by Valenzuela et al. (22) and suggests that PDGF- $\beta$ receptor activation could be implicated in the down-regulation of such HVR-related kinases in the brainstem.

How can we reconcile the aforementioned pathways that were identified in the adult with the patterning of HVD in the developing animal? First and foremost, we do not suggest that PDGF- $\beta$ receptor activation is the only mechanism underlying HVD. In fact, HVD was attenuated but still present after administration of the PDGF- $\beta$ receptor antagonist (Fig. 1). Second, we have previously demonstrated that the paucity of nNOS expression in the brainstem of the developing rat precludes the ability to sustain increased ventilatory output during hypoxia (7). Third, there are clearly other neurotransmitters implicated in HVD, such as GABA (5), adenosine (6), and opioid receptors (8). Finally, the immature rat displays increased dependency of ventilatory drive on PKC activity (32). Thus, as previously proposed by Valenzuela et al. (22), if one of the major effects linked to PDGF- $\beta$ receptor activation consists in the down-regulation of PKC activity in glutamatergic HVR neurons, the present data could provide a plausible mechanism for the enhanced role of PDGF- $\beta$ receptor on HVD in the youngest rats. In this context, higher expression and activity of PDGF- $\beta$ receptor during hypoxia in these glutamatergic HVR neurons would lead to a more pronounced deactivation of PKC, and accordingly to enhanced reductions in ventilatory output.

Expression of PDGF- $\beta$ receptors. Previous investigators have shown that both the PDGF-B chain and the PDGF- $\beta$ receptor are widely expressed in CNS neurons of the monkey, albeit with heterotopic distribution, such that the hippocampus, hypothalamus, posterior pituitary, amygdala, and nuclei within the brainstem show the highest degree of immunostaining (33). Furthermore, in transgenic mice in which the chloramphenicol acetyltransferase gene was placed under transcriptional control of the PDGF-B chain promoter, preferential expression occurred in the cortex, hippocampus, and brainstem, and was highest around birth, suggesting that PDGF-B is developmentally regulated (33). Similar results showing increased PDGF- $\beta$ receptor expression in the neonatal rat brain were reported by Smits and colleagues (34), while the expression of PDGF- $\alpha$ receptors increases throughout E15 to P14 and then decreases with advancing age $(35,36)$. Our current findings are in close agreement with previous studies, and extend such observations to the dorsocaudal brainstem, a brain region that plays a major role in the ventilatory response to hypoxia.

In summary, we present evidence indicating that the characteristically pronounced ventilatory reduction in response to sustained hypoxia, as measured in the developing rat, correlates with levels of PDGF- $\beta$ receptor expression. However, activation of PDGF- $\beta$ receptors does not seem to play a role in the early phase of the HVR or in the ventilatory response to hypercapnia.

Acknowledgments. The authors thank Dr. Elizabeth Buchdunger, Novartis Pharma AG, Basel, Switzerland, for graciously providing CGP 57148B. D.G. and E.G. are supported by grants from the National Institutes of Health (HL-65270 HL-63912, HL-66358, P20 RR-15576) and the American Heart Association (AHA-0050442N).

\section{REFERENCES}

1. Powell FL, Milsom WK, Mitchell GS 1998 Time domains of the hypoxic ventilatory response. Respir Physiol 112:123-134

2. Eden GJ, Hanson MA 1987 Maturation of the respiratory response to acute hypoxia in the newborn rat. J Physiol (Lond) 392:1-9

3. Mortola JP 1999 How newborn mammals cope with hypoxia. Respir Physiol 116:95103

4. Lin J, Suguihara C, Huang J, Hehre D, Devia C, Bancalari E 1996 Effect of $\mathrm{N}$-methyl-D-aspartate receptor blockade on hypoxic ventilatory response in unanesthetized piglets. J Appl Physiol 80:1759-1763

5. Huang J, Suguihara C, Hehre D, Lin J, Bancalari E 1994 Effects of GABA receptor blockage on the respiratory response to hypoxia in sedated newborn piglets. J Appl Physiol 77:1006-1010

6. Elnazir B, Marshall JM, Kumar P 1996 Postnatal development of the pattern of respiratory and cardiovascular response to systemic hypoxia in the piglet: the roles of adenosine. J Physiol (Lond) 492:573-585

7. Gozal D, Gozal E, Torres JE, Gozal YM, Nuckton TJ, Hornby PJ 1997 Nitric oxide modulates ventilatory responses to hypoxia in conscious developing rats. Am J Respir Crit Care Med 155:1755-1762 
8. Moss IR 2000 Respiratory responses to single and episodic hypoxia during development: mechanisms of adaptation. Respir Physiol 121:185-197

9. Gozal D, Simakajornboon N, Czapla MA, Xue YD, Gozal E, Vlasic V, Lasky JA, Liu JY 2000 Platelet-derived growth factor $\beta$ receptor activation modulates components of the hypoxic ventilatory response. J Neurochem 74:310-319

10. Bartlett Jr D, Tenney SM 1970 Control of breathing in experimental anemia. Respir Physiol 10:384-395

11. Pappenheimer JR 1977 Sleep and respiration of rats during hypoxia. J Physiol (Lond) 266:191-207

12. Epstein RA, Epstein MAF, Haddad GG, Mellins RB 1980 Practical implementation of the barometric method for measurement of tidal volume. J Appl Physiol 49:1107-1115

13. Mortola JP, Frappell PB 1998 On the barometric method for measurements of ventilation, and its use in small animals. Can J Physiol Pharmacol 76:937-944

14. Buchdunger E, Zimmerman J, Mett H, Meyer T, Müller M, Druker BJ, Lydon NB 1996 Inhibition of the Abl protein-tyrosine kinase in vitro and in vivo by a 2-phenylaminoprimidine derivative. Cancer Res 56:100-104

15. Ohtake PJ, Simakajornboon N, Fehniger MD, Xue YD, Gozal D 2000 NMDA receptor expression in the nucleus tractus solitarii and maturation of hypoxic ventilatory response in the rat. Am J Respir Crit Care Med 162:1140-1147

16. Whitney GM, Ohtake PJ, Xue YD, Simakajornboon N, Gozal D 2000 AMPA glutamate receptors and respiratory control in the developing rat: anatomical and pharmacological aspects. Am J Physiol 278:R520-R528

17. Gozal E, Roussel AL, Holt GA, Gozal L, Gozal YM, Torres JE, Gozal D 1998 Protein kinase $\mathrm{C}$ modulation of the ventilatory response to hypoxia in the nucleus tractus solitarius of the conscious rat. J Appl Physiol 84:1982-1990

18. Mourek J 1959 Oxygen consumption during ontogenesis in rats in environments with a high and low oxygen content. Physiol Bohemoslov 8:106-111

19. Ang RC, Hoop B, Kazemi H 1992 Role of glutamate as the central neurotransmitter in the hypoxic ventilatory response. J Appl Physiol 72:1480-1487

20. Ohtake PJ, Torres JE, Gozal YM, Graff GR, Gozal D 1998 NMDA receptors mediate cardiorespiratory responses to afferent peripheral chemoreceptor input in the conscious rat. J Appl Physiol 84:853-861

21. Mizusawa A, Ogawa H, Kikuchi Y, Hida W, Kurosawa H, Okabe S, Takishima T, Shirato K 1994 In vivo release of glutamate in nucleus tractus solitarii of the rat during hypoxia. J Physiol (Lond) 478:55-65

22. Valenzuela CF, Xiong Z, MacDonald JF, Weiner JL, Frazier CJ, Dunwiddie TV, Kazlauskas A, Whiting PJ, Harris RA 1996 Platelet-derived growth factor induces a long-term inhibition of $\mathrm{N}$-methyl-d-aspartate receptor function. J Biol Chem 271:16151-16159

23. Gozal D, Torres JE, Gozal YM, Littwin SM 1996 Effect of nitric oxide synthase inhibition on cardiorespiratory responses in the conscious rat. J Appl Physiol 81:2068-2077
24. Gozal D, Gozal E, Gozal YM, Torres JE 1996 Nitric oxide synthase isoforms and peripheral chemoreceptor stimulation in conscious rats. Neuroreport 7:1145114824

25. Gozal D, Gozal E, Graff GR 1998 Evidence for a central role of protein kinase C in modulation of the hypoxic ventilatory response in the rat. Adv Exp Med Biol 10:45-49

26. Gozal D, Graff GR, Torres JE, Khicha SG, Nayak GS, Simakajornboon N, Gozal E 1998 Cardiorespiratory responses to systemic administration of a protein kinase C inhibitor in the conscious rat. J Appl Physiol 84:641-648

27. Gozal D, Graff GR, Gozal E, Torres JE 1998 Modulation of the hypoxic ventilatory response by $\mathrm{Ca}^{2+}$-dependent and $\mathrm{Ca}^{2+}$-independent protein kinase $\mathrm{C}$ in the nucleus tractus solitarii of conscious rats. Respir Physiol 112:283-290

28. Czapla MA, Simakajornboon N, Holt GA, Gozal D 1999 Tyrosine kinase inhibitors within the dorsocaudal brainstem modulate the ventilatory response to hypoxia in the conscious rat. J Appl Physiol 87:363-369

29. Gozal E, Simakajornboon N, Dausman JD, Xue YD, Corti M, El-Dahr S, Gozal D 1999 Hypoxia selectively activates SAPK/JNK-2-AP-1 pathway in the nucleus tractus solitarii of the conscious rat. J Neurochem 73:665-674

30. Simakajornboon N, Gozal E, Gozal YM, Gozal D 2000 Hypoxia induces activation of a NMDA glutamate receptor-protein kinase C pathway in the dorsocaudal brainstem of the conscious rat. Neurosci Lett 278:17-20

31. Gozal D, Gozal E 1997 Hypoxic ventilatory roll-off is associated with decreases in protein kinase $\mathrm{C}$ activation within the nucleus tractus solitarius of the rat. Brain Res 774:246-249

32. Bandla HPR, Simakajornboon N, Graff GR, Gozal D 1999 Protein kinase C modulates ventilatory patterning in the developing rat. Am J Respir Crit Care Med 159:968-973

33. Sasahara M, Fries JWU, Raines EW, Gown AM, Westrum LE, Frosch MP, Bonthron DT, Ross R, Collins T 1991 PDGF-B chain in neurons of the central nervous system, posterior pituitary, and in a transgenic model. Cell 64:217-227

34. Smits A, Kato M, Westermark B, Nister M, Heldin CF, Funa K 1991 Neurotrophic activity of platelet-derived growth factor (PDGF): rat neuronal cells possess functional PDGF- $\beta$ type receptors and respond to PDGF. Proc Natl Acad Sci USA 88:8159-8163

35. Yeh HJ, Silos-Santiago I, Wang YX, George RJ, Snider WD, Deuel TF 1993 Developmental expression of the platelet-derived growth factor $\alpha$ receptor gene in mammalian central nervous system. Proc Natl Acad Sci USA 90:1952-1956

36. Reddy UR, Pleasure D 1992 Expression of platelet-derived growth factor (PDGF) and PDGF receptor genes in the developing rat brain. J Neurosci Res 31:670-677 